\title{
Genetic and other risk factors for suicidal ideation and the relationship with depression
}

\author{
R. Dutta ${ }^{1 *}$, H. A. Ball ${ }^{1}$, S. H. Siribaddana ${ }^{2,3}$, A. Sumathipala ${ }^{1,2,4}$, S. Samaraweera ${ }^{2}$, P. McGuffin ${ }^{1}$ \\ and M. Hotopf $\mathbf{f}^{1}$ \\ ${ }^{1}$ Department of Psychological Medicine, Institute of Psychiatry, Psychology and Neurosciences, King's College London, London SE5 9RJ, UK \\ ${ }^{2}$ Sri Lanka Twin Registry, Institute of Research and Development, Battaramulla, Sri Lanka \\ ${ }^{3}$ Faculty of Medicine, Rajarata University of Sri Lanka, Saliyapura, Sri Lanka \\ ${ }^{4}$ Keele University, Stoke-on-Trent, UK
}

Background. There is a genetic contribution to the risk of suicide, but sparse prior research on the genetics of suicidal ideation.

\begin{abstract}
Methods. Active and passive suicidal ideation were assessed in a Sri Lankan population-based twin registry $(n=3906$ twins) and a matched non-twin sample $(n=2016)$. Logistic regression models were used to examine associations with socio-demographic factors, environmental exposures and psychiatric symptoms. The heritability of suicidal ideation was assessed using structural equation modelling.

Results. The lifetime prevalence of any suicidal ideation was $13.0 \%$ (11.7-14.3\%) for men; $21.8 \%$ (20.3-23.2\%) for women, with no significant difference between twins and non-twins. Factors that predicted suicidal ideation included female gender, termination of marital relationship, low education level, urban residence, losing a parent whilst young, low standard of living and stressful life events in the preceding 12 months. Suicidal ideation was strongly associated with depression, but also with abnormal fatigue and alcohol and tobacco use. The best fitting structural equation model indicated a substantial contribution from genetic factors (57\%; CI 47-66) and from non-shared environmental factors (43\%; CI 34-53) in both men and women. In women this genetic component was largely mediated through depression, but in men there was a significant heritable component to suicidal ideation that was independent of depression.

Conclusions. These are the first results to show a genetic contribution to suicidal ideation that is independent of depression outside of a high-income country. These phenomena may be generalizable, because previous research highlights similarities between the aetiology of mental disorders in Sri Lanka and higher-income countries.
\end{abstract}

Received 7 October 2016; Revised 16 March 2017; Accepted 21 March 2017; First published online 8 May 2017

Key words: Depression, genetics, suicidal ideation, twin study.

\section{Introduction}

The World Health Organisation (WHO) estimates that $75 \%$ of suicides occur in low and middle-income countries (LMICs), yet research from these areas is scarce (Hawton, 2014; WHO, 2014). Sri Lanka, the setting for this study, ranks fourth out of 172 countries (WHO, 2014) with a suicide rate of $28.8 / 100000 /$ year compared with a global rate of $11.4 / 100000 /$ year in 2012.

Suicidal ideation is a risk factor for completed suicide (O'Connor \& Nock, 2014) and there are marked

\footnotetext{
* Address for correspondence: Dr R. Dutta, Senior Clinical Lecturer, Department of Psychological Medicine, Institute of Psychiatry, Psychology and Neurosciences, King's College London, Weston Education Centre, Cutcombe Rd, London SE5 9RJ, UK.

(Email: rina.dutta@kcl.ac.uk)

† Joint first authors.
}

international differences in the prevalence. The SUPRE-MISS study (Bertolote et al. 2005) reported prevalence of suicidal ideation ranging from $2.6 \%$ in Chennai, India to $25.4 \%$ in Durban, South Africa.

Family studies in high-income countries suggest that completed suicide and suicide attempts may be familial and at least partly independent from the heritability of psychiatric disorders (Brent \& Melhem, 2008).

There is contradictory evidence whether suicidal ideation is part of a familial phenotype for suicidal behaviour. Two large-scale adult epidemiological twin studies in Australia (Statham et al. 1998) and the USA (Fu et al. 2002) have suggested there is heritability for lifetime suicidal ideation as part of a suicidal spectrum phenotype (Schosser et al. 2011), whereas other studies suggest ideation is heritable via depression (Brent et al. 1996; Lieb et al. 2005; Brent, 2010).

A study using a molecular genetic risk score to predict depression, found it also predicted suicidal

This is an Open Access article, distributed under the terms of the Creative Commons Attribution licence (http://creativecommons.org/licenses/by/4.0/), which permits unrestricted re-use, distribution, and reproduction in any medium, provided the original work is properly cited. 
self-injuries (Maciejewski et al. 2017). However molecular genetic studies of suicidality have failed to identify replicable associations showing genome-wide significance (Mirkovic et al. 2016).

We aimed (1) to describe the prevalence and associations of active and passive suicidal ideation in a Sri Lankan population; (2) to investigate the patterns of heritability of suicidal ideation in a middle income country, where the cultural context of contemplating suicide is expected to be different from the high-income countries studied to date (Bertolote \& Fleischmann, 2002; Sumathipala et al. 2004); (3) to examine whether some of the heritability of suicidal ideation is independent of depression and (4) to use a discordant MZ twin design, to identify specific measured environmental risk factors that act independently of genetic influences.

\section{Methods}

The study received approvals from King's College London, the University of Sri Jayewardanepura, and the WHO's Research Ethics Committees.

\section{Study design}

The Colombo Twin And Singleton Study (CoTASS) is a population-based twin study with a comparable nontwin sample. Full details of the design of the study are described elsewhere (Siribaddana et al. 2008). Briefly, the study took place in the Colombo District of Sri Lanka, a mixed urban and rural area with a population of 2.2 million, which includes the island's capital.

Twins were identified by adding a question to the update of the annual census, asking whether the householder knew of any twins or triplets. We identified 19302 individuals, of whom 4387 were randomly selected for the present study with a participation rate of $91.7 \%(n=4024)$. The present analyses use 3906 twin individuals, including 830 complete MZ pairs and 1110 complete DZ pairs (the remainder being unpaired twins). We conducted a parallel study of non-twins, randomly sampled from the same local areas from which twins were recruited. 2311 non-twins were selected and eligible to participate, of whom 2016 (87.2\%) participated. The twin and non-twin samples had similar sex profiles, although the twins (mean age 34.0 years) were younger than the singletons (mean age 43.5 years) (Siribaddana et al. 2008). We included all consenting individuals aged 15 years or older who spoke sufficient Sinhala to understand the interview. Individuals were excluded if they failed a mini mental state examination, or where interviews were conducted via a proxy. Interviews took place between 2006 and 2007.
Trained lay researchers visited the participants' homes and interviewed each twin separately. Interviews and questionnaires were translated at least twice independently in a culturally sensitive manner, then formally reviewed and trialled (Siribaddana et al. 2008).

\section{Measures}

Assessment of lifetime-ever suicidal ideation included two items indexing passive ideation ('have you felt there is no point in living anymore'; 'have you felt that dying is better than living') and one indexing active ideation ('have you thought of committing suicide'). From these items, binary variables were created indicating a positive response to 'active ideation', 'passive ideation' (without active ideation), or 'any suicidal ideation'

We used the Composite International Diagnostic Interview (CIDI) (Robins et al. 1988), because it is a diagnostic interview for use by lay-interviewers. Our definition of lifetime-ever depression was slightly less stringent than conventional DSM-IV criteria for a depressive episode (APA, 2000): we ignored the bereavement criterion and the opt-out due to mixed states. We also disregarded the requirement for functional impairment, because it is considered less valid in this population, and the characteristics of the phenotype were very similar with or without this requirement (Ball et al. 2010b). The CIDI was also used to index tobacco and alcohol use and abuse. Lifetime ever tobacco use was measured as daily use for 1 month or more of cigarettes, cigars, a pipe, snuff or chewed tobacco. Lifetime consumption of at least 12 alcoholic drinks was considered alcohol use. Alcohol abuse was defined as a maladaptive pattern of drinking leading to clinically significant impairment, manifested by one or more of the following: failure to fulfil major role obligations at work/school/home; use when a physical hazard; use-related legal problems; use despite social/interpersonal problems due to alcohol.

The Chalder Fatigue Questionnaire (Chalder et al. 1993) was also administered. 'Abnormal fatigue' was defined as having at least three of 11 symptoms present at least 'more than usual' over the past month (there were no medical exclusions).

Life events were assessed using the List of Threatening Experiences (Brief Life Events Questionnaire) (Brugha \& Cragg, 1990) over the past 12 months. The Childhood Experience of Care and Abuse Questionnaire (CECA-Q) (Bifulco et al. 2005) was used to assess experience of death or separation from either parent prior to age 17 years.

A further questionnaire based on the Sri Lankan census assessed socio-demographic characteristics and 
current living environment. Items probed a wide spectrum of household characteristics rather than just detecting the poorest end of the distribution, and these were summed to create a composite variable. We used a binary summary of this composite, indicating those in the top $3 / 5$ of the distribution $v$. the bottom $2 / 5$, because the association with depression was nonlinear (Ball et al. 2010b). This questionnaire also asked about the number of months worked in the previous 12 months, marital status, urban residence and years of education.

\section{Statistical analysis}

Epidemiological analyses (twins and non-twins)

A database combining the twin and non-twin data were constructed in SPSS-10. Analyses were performed in Stata version 9.2 (Stata-Corp, College Station, Texas). Analyses were corrected for the non-independence of twins within pairs, using the Huber-White-Sandwich (robust) estimator of variance (Williams, 2000).

Multiple logistic regression analyses were used to identify socio-demographic factors that were independently associated with suicidal ideation. These factors were then controlled for in subsequent logistic regression models, which examined the association with social circumstances, psychiatric symptoms and behaviours.

\section{Genetic analyses of 'any suicidal ideation' (twins only)}

We used standard twin modelling as implemented in Mx for Windows (www.vcu.edu/mx/index.html) to estimate the relative contributions of additive genetics (A), shared environments (C) and non-shared environments (E) to suicidal ideation. This is done by examining the similarity of monozygotic (MZ) pairs of twins, and comparing this with the similarity of dizygotic (DZ) pairs of twins. For example, higher correlations within $\mathrm{MZ}$ compared with $\mathrm{DZ}$ pairs indicates $\mathrm{A}$, because shared genes are the only explanation for greater similarity. $\mathrm{C}$ is indicated by any environmental exposure that makes twins within a pair (both $\mathrm{MZ}$ and DZ) similar to one another (e.g. family-wide poverty). $\mathrm{E}$ is indicated by any environmental factor that makes one twin different from the co-twin (e.g. an accident that affects only one twin within a pair), and so E is calculated as the amount of dissimilarity within $\mathrm{MZ}$ pairs (note $\mathrm{E}$ also incorporates measurement error). Latent ACE variable parameter constraints were applied, then standardized. It is possible to calculate a parameter indexing dominance genetic variance (D) instead of $\mathrm{C}$; this is indicated if the correlation for $\mathrm{MZ}$ pairs is greater than double that for DZ pairs.
We examined 'any suicidal ideation' (rather than active or passive separately) because there were only a small number of 'concordant affected' pairs (those in which both twins reported ideation). This also limited our ability to generate latent ACE variable parameter models to univariate only; bivariate analyses were performed using logistic regression models (see c and d below).

The estimated genetic model is compared with the observed data in order to produce the maximum likelihood fit of the model. This genetic model fit is compared with that of a fully saturated model of the correlations. Models that are nested within one another can be compared using a chi-squared test.

Tetrachoric correlations were used because the data are binary. This method assumes that liability to suicidal ideation is normally distributed throughout the population, with affected individuals having exceeded a certain threshold of liability. Liability thresholds were estimated separately for men and women. The effect of age was accounted for through regression coefficients on the liability thresholds, as has been described previously (Reynolds et al. 2006).

\section{Genetic analyses of the relationship between 'any suicidal} ideation' and depression (twins only)

Logistic regression models were run, which predicted 'any suicidal ideation' in one twin ('proband') from the same variable in the co-twin. This indicates familial contributions to suicidal ideation. Next, the models were re-run while controlling for depression in the co-twin, to indicate whether the familial influences on suicidal ideation are independent of familial influences on depression. The age control for these analyses was linear.

Finally, the results were compared across zygosity groups. A significant interaction according to zygosity (i.e. a stronger association in MZs than DZs) indicates the existence of a genetic contribution to suicidal ideation, which is independent of depression.

\section{MZ differences models: 'true' environmental associations}

The social circumstances identified to correlate with suicidal ideation [in the epidemiological analysis described in (a)] might be construed as discrete insults that impact on an individual, which then cause the outcome (suicidal ideation). An alternative explanation is that these social circumstances are markers of associated genetic tendencies (A) or wider aspects of family upbringing $(\mathrm{C})$. If however, a correlation remains after we have ruled out the effects of A and C, there is more chance it is involved in a truly environmental causal pathway. By looking at the differences within $\mathrm{MZ}$ pairs of twins, it is possible to confirm whether a social 
circumstance is associated with suicidal ideation via non-shared environments (E). Therefore, we measured the difference in suicidal ideation within each pair of MZ twins, and separately measured the difference in the social circumstances within each pair of $\mathrm{MZ}$ twins. Ordered logistic regression models were used to examine the association between the difference in suicidal ideation within each $M Z$ twin pair, with the difference in social circumstances within each $M Z$ twin pair.

The twin analyses described in (c) and (d) were only controlled for age, sex and ethnicity, on the basis that these factors are determined at birth, so are temporally prior and could not be an 'outcome' of suicidal ideation or depression.

\section{Results}

Data are presented for 5922 participants. Reported lifetime ever suicidal ideation was $13.0 \%$ (11.7-14.3) for men and $21.8 \%$ (20.3-23.2) for women. Overall $6.2 \%$ (CI 5.6-6.9) had experienced active ideation, and $11.5 \%$ (CI 10.7-12.4) reported passive ideation only (Table 1). Adjusting only for age, owing to the difference in mean age between twins and non-twins in the study, there was no significant difference in prevalence of any suicidal ideation (twins 16.9\%, CI 15.618.2, non-twins $19.4 \%$, CI 17.7-21.1, $p=0.51$ ).

\section{Socio-demographic factors}

Suicidal ideation was consistently associated with female sex, being widowed, separated or divorced and low educational attainment (Table 1). Active ideation was most common amongst 30-44 year olds, whereas passive ideation became more prevalent with increasing age. Ethnicity was not associated with 'any suicidal ideation', but being Muslim was a protective factor with regard to active ideation. Urban living was associated with passive ideation.

\section{Social circumstances}

Parental loss as a child, one or more life events, underemployment (working 2-10 months in the previous 12 months) and having a low standard of living were uniformly associated with all types of suicidal ideation (Table 2).

\section{Psychiatric symptoms and behaviours}

There were robust associations between all types of suicidal ideation and depression, abnormal fatigue and alcohol abuse (Table 2). Depression was more strongly associated with active than passive ideation.
Alcohol use (excluding alcohol abuse) was not associated with suicidal ideation; whereas alcohol abuse was associated with all types of suicidal ideation. Tobacco use was associated with active but not passive suicidal ideation. Alcohol abuse was identified solely in males: $9.2 \%$ of men abused alcohol. A very low proportion $(3.7 \%)$ of women used alcohol compared with $63.1 \%$ of men, and only $2.0 \%$ of women used tobacco compared with $38.4 \%$ of men.

\section{Twin correlations and genetic models}

Twin tetrachoric correlations were calculated in $\mathrm{Mx}$, controlling for age. One linear age parameter was used for each sex. The age parameter was statistically significant so was retained for the purposes of calculating ACE parameters. The thresholds (which indicate prevalence) could not be equated across sex (due to higher prevalence in women than men), but thresholds could be equated across zygosity within men and women, without significant reduction in fit (indicating that the prevalence did not differ across zygosity groups).

The tetrachoric correlations in women (MZ: 0.53; DZ: 0.40$)$ suggest that a mixture of additive genetic and common environmental factors contribute to familial similarity in suicidal ideation. The tetrachoric correlations in men (MZ: 0.63; DZ: 0.10) suggest a dominance genetic pattern, since the figure for $M Z s$ is more than double that for DZs (however, it should be noted that there were only four DZ concordant affected male pairs, making the tetrachoric correlation estimate imprecise). We therefore tested model fit for both ACE and ADE in men (Table 3), and both were an adequate fit. However, the subsequent models showed that it is possible to drop the $\mathrm{C}$ or $\mathrm{D}$ parameters and this is reflected in Table 4 where the confidence intervals for the $\mathrm{C}$ and $\mathrm{D}$ parameters include zero. Therefore the correlations were adequately modelled with only A and E parameters (Model 7, Tables 3 \& 4: change in $-2 \log$ likelihood $=0.724, \mathrm{df}=2, p=0.696$, change in AIC -3.276). Furthermore, the estimated values of $A$ and $E$ could be equated across sex without significant loss of fit (Model 8, Tables $3 \& 4$ : change in $-2 \log$ likelihood 0.930, $\mathrm{df}=3, p=0.818$, change in AIC $-5.070)$. Therefore, the variance in liability to suicidal ideation, in both men and women, was influenced by additive genetic factors 57\% (95\% CI 47-66) and nonshared environmental factors $43 \%$ (95\% CI 34-53).

The tetrachoric correlation for DZ opposite sex pairs was 0.31 . This is mid-way between the figure for allmale and all-female DZ pairs, suggesting that sex differences are quantitative rather than qualitative (i.e. the same individual aetiological factors affect men and women, but to different degrees). We were able 


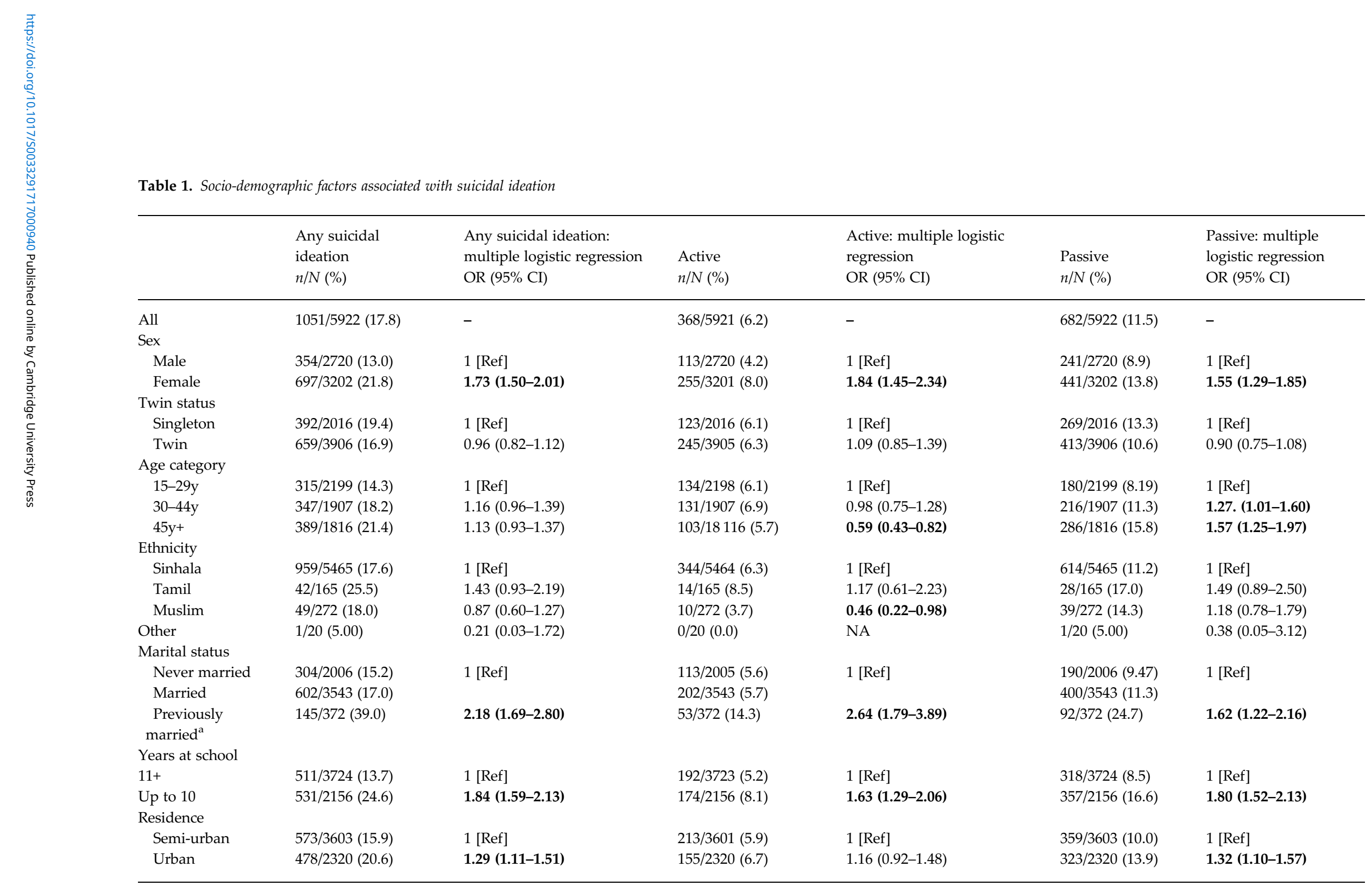

${ }^{a}$ Comparing previously married (widowed OR separated OR divorced), with combined group of never married OR married.

Where $n$ differs by 1 or 2 within a row, this is due to missing data. Bold values indicate $p<0.05$. 
Table 2. Environmental exposures, psychiatric symptoms and behaviours associated with suicidal ideation

\begin{tabular}{|c|c|c|c|c|c|c|}
\hline & $\begin{array}{l}\text { Any suicidal ideation } \\
n / N(\%)\end{array}$ & $\begin{array}{l}\text { Any suicidal ideation, } \\
\text { multiple logistic regression } \\
\text { OR }(95 \% \mathrm{CI})\end{array}$ & $\begin{array}{l}\text { Active } \\
n / N(\%)\end{array}$ & $\begin{array}{l}\text { Active: multiple logistic } \\
\text { regression } \\
\text { OR }(95 \% \mathrm{CI})\end{array}$ & $\begin{array}{l}\text { Passive } \\
n / N(\%)\end{array}$ & $\begin{array}{l}\text { Passive: multiple logistic } \\
\text { regression } \\
\text { OR }(95 \% \mathrm{CI})\end{array}$ \\
\hline \multicolumn{7}{|c|}{ Environmental exposure models } \\
\hline \multicolumn{7}{|c|}{ Months worked in past 12 months ${ }^{a}$} \\
\hline $11-12$ & $373 / 2452(15.2)$ & 1 [Ref] & $135 / 2452(5.5)$ & 1 [Ref] & 238/2452 (9.7) & 1 [Ref] \\
\hline $2-10$ & $158 / 656(24.1)$ & $1.53(1.22-1.91)$ & $66 / 656(10.1)$ & $1.62(1.17-2.24)$ & $92 / 656(14.0)$ & $1.32(1.00-1.75)$ \\
\hline $0-1$ & $498 / 2588(19.2)$ & $0.96(0.81-1.13)$ & $163 / 2587(6.3)$ & $0.81(0.62-1.06)$ & $334 / 2588(12.9)$ & $1.06(0.87-1.30)$ \\
\hline \multicolumn{7}{|c|}{ Parents: died/separated from them before $17 \mathrm{yrs}^{\mathrm{a}}$} \\
\hline No & $678 / 4327(15.7)$ & 1 [Ref] & $219 / 4326(5.1)$ & 1 [Ref] & $458 / 4327(10.6)$ & 1 [Ref] \\
\hline Yes & $370 / 1576(23.5)$ & $1.56(1.34-1.82)$ & $147 / 1576(9.3)$ & $1.86(1.48-2.34)$ & 223/1576 (14.2) & $1.29(1.08-1 \cdot 55)$ \\
\hline \multicolumn{7}{|c|}{ Life events in preceding $\mathrm{yr}^{\mathrm{a}}$} \\
\hline None & 255/2517 (10.1) & 1 [Ref] & 64/2517 (2.5) & 1 [Ref] & 191/2517 (7.6) & 1 [Ref] \\
\hline $1+$ & $790 / 3388(23.3)$ & $2.61(2.22-3.06)$ & $300 / 3387(8.9)$ & $3.53(2.68-4.67)$ & $489 / 3388(14.4)$ & $1.96(1.63-2.36)$ \\
\hline \multicolumn{7}{|l|}{ Standard of living ${ }^{a}$} \\
\hline Top $3 / 5$ & 475/3564 (13.3) & 1 [Ref] & $155 / 3563(4.4)$ & 1 [Ref] & $319 / 3564(8.95)$ & 1 [Ref] \\
\hline Bottom $2 / 5$ & $576 / 2358(24.4)$ & $1.78(1.53-2.07)$ & $213 / 2358(9.0)$ & $1.97(1.57-2.48)$ & $363 / 2358(15.4)$ & $1.52(1.28-1.82)$ \\
\hline \multicolumn{7}{|c|}{ Psychiatric symptom and behaviour models } \\
\hline \multicolumn{7}{|c|}{ Depression $^{\mathrm{b}}$} \\
\hline Absent & $744 / 5261$ (14.1) & 1 [Ref] & $211 / 5260(4.0)$ & 1 [Ref] & $532 / 5261(10.1)$ & 1 [Ref] \\
\hline Present & 307/661 (46.4) & $3.75(3.09-4.55)$ & 157/661 (23.8) & $5.32(4.12-6.88)$ & 150/661 (22.7) & $1.82(1.44-2.30)$ \\
\hline \multicolumn{7}{|l|}{ Abnormal fatigue $^{\mathrm{b}}$} \\
\hline Absent & 624/4762 (13.1) & 1 [Ref] & 214/4761 (4.5) & 1 [Ref] & 409/4762 (8.6) & 1 [Ref] \\
\hline Present & 423/1147 (36.9) & $2.55(2.16-3.02)$ & 153/1147 (13.3) & $2.05(1.58-2.65)$ & 270/1147 (23.5) & $2.27(1.88-2.75)$ \\
\hline \multicolumn{7}{|l|}{ Alcohol abuse $^{\mathrm{b}}$} \\
\hline No use & $\begin{array}{l}\text { 745/4068 (18.3) } \\
\text { Men only: 83/985 } \\
(8.4)\end{array}$ & 1 [Ref] & $\begin{array}{l}\text { 266/4067 (6.5) } \\
\text { Men only: 25/ } \\
985 \text { (2.5) }\end{array}$ & 1 [Ref] & $\begin{array}{l}\text { 478/4068 (11.8) } \\
\text { Men only: 58/985 } \\
\text { (5.9) }\end{array}$ & 1 [Ref] \\
\hline Use but not abuse & $\begin{array}{l}\text { 229/1603 (14.3) } \\
\text { Men only: 194/1484 } \\
\text { (13.1) }\end{array}$ & $1.16(0.91-1.48)$ & $\begin{array}{l}\text { 70/1603 (4.4) } \\
\text { Men only: 56/ } \\
1484(3.8)\end{array}$ & $1.08(0.73-1.59)$ & $\begin{array}{l}\text { 159/1603 (9.9) } \\
\text { Men only: 138/ } \\
1484 \text { (9.3) }\end{array}$ & $1.19(0.90-1.57)$ \\
\hline Abuse & $\begin{array}{l}\text { 76/249 (30.5) } \\
\text { Men only: } 76 / 249 \\
\text { (30.5) }\end{array}$ & $2.29(1.55-3.39)$ & $\begin{array}{l}\text { 31/249 (12.5) } \\
\text { Men only: } 31 / \\
249 \text { (12.5) }\end{array}$ & $2.15(1.23-3.76)$ & $\begin{array}{l}\text { 45/249 (18.1) } \\
\text { Men only: } 45 / 249 \\
\text { (18.1) }\end{array}$ & $1.97(1.24-3.14)$ \\
\hline \multicolumn{7}{|l|}{ Tobacco use $^{\mathrm{b}}$} \\
\hline Absent & $827 / 4813(17.2)$ & 1 [Ref] & 286/4812 (5.9) & 1 [Ref] & $540 / 4813(11.2)$ & 1 [Ref] \\
\hline Present & $223 / 1108(20.1)$ & $1.45(1.13-1.85)$ & $81 / 1108(7.3)$ & $2.01(1.37-2.95)$ & $142 / 1108(12.8)$ & $1.14(0.87-1.50)$ \\
\hline
\end{tabular}

Bold values indicate $p<0.05$.

${ }^{a}$ Environmental exposure models controlled for socio-demographic factors: sex, age, ethnicity, being previously married, years of schooling and urban residence.

${ }^{b}$ Psychiatric symptoms and behaviour models controlled for the above socio-demographic factors and mutually controlled for the measures of depression, abnormal fatigue, alcohol use and abuse and tobacco use. 
Table 3. Genetic model fit statistics for 'any suicidal ideation'

\begin{tabular}{|c|c|c|c|c|c|c|c|}
\hline Model & $\begin{array}{l}-2 \log \\
\text { likelihood }\end{array}$ & $\begin{array}{l}\text { Degrees of } \\
\text { freedom (df) }\end{array}$ & $\begin{array}{l}\text { Compare to } \\
\text { model }\end{array}$ & $\begin{array}{l}\text { Change in }-2 \\
\text { log likelihood }\end{array}$ & $\begin{array}{l}\text { Change in } \\
\text { df }\end{array}$ & $p$ & $\begin{array}{l}\text { Change in } \\
\text { AIC }\end{array}$ \\
\hline 1. Saturated & 3300.893 & 3827 & - & - & - & - & - \\
\hline 2. ACE_ACE & 3302.854 & 3828 & 1 & 1.961 & 1 & 0.16 & -0.039 \\
\hline 3. ADE_ACE & 3303.414 & 3828 & 1 & 2.521 & 1 & 0.112 & 0.521 \\
\hline 4. AE_ACE & 3303.430 & 3829 & 3 & 0.016 & 1 & 0.900 & -1.984 \\
\hline 5. ADE_AE & 3303.970 & 3829 & 3 & 0.556 & 1 & 0.456 & -1.444 \\
\hline 6. ADE_CE & 3314.878 & 3829 & 3 & 11.464 & 1 & 0.001 & 9.464 \\
\hline 7. AE_AE & 3304.138 & 3830 & 3 & 0.724 & 2 & 0.696 & -3.276 \\
\hline $\begin{array}{l}\text { 8. AE (equated } \\
\text { across sex) }\end{array}$ & 3304.344 & 3831 & 3 & 0.930 & 3 & 0.818 & -5.070 \\
\hline
\end{tabular}

AIC, Akaike's information criterion.

Note 1: Because the correlations reported above suggested dominance genetics in men, so an ADE model was attempted in men as well as the more standard ACE model.

Note 2: male model written first, eg ADE_ACE means a model using ADE in men and ACE in women.

Table 4. Percentage of variance in 'any suicidal ideation' explained by ACDE

\begin{tabular}{|c|c|c|c|c|c|c|}
\hline \multirow[b]{2}{*}{ Model } & \multicolumn{3}{|c|}{ Male parameters } & \multicolumn{3}{|c|}{ Female parameters } \\
\hline & A & C or D & E & A & $\mathrm{C}$ & $\mathrm{E}$ \\
\hline 2. ACE_ACE & $57(21-76)$ & $3(0-30)$ & $40(24-61)$ & $30(0-65)$ & $24(0-55)$ & $47(35-60)$ \\
\hline 3. ADE_ACE & $57(10-77)$ & $4(0-57)$ & $38(23-58)$ & $41(11-66)$ & $13(0-42)$ & $45(34-58)$ \\
\hline 7. AE_AE & $60(41-76)$ & - & $40(24-59)$ & $55(43-67)$ & - & $45(33-57)$ \\
\hline 8. AE (equated across sex) & $57(47-66)$ & - & $43(34-53)$ & $57(47-66)$ & - & $43(34-53)$ \\
\hline
\end{tabular}

Note: only standardized estimates of variance are presented.

to calculate the tetrachoric correlations separately for active and passive ideation among women. These correlations (active ideation $\mathrm{MZ}$ 0.52, DZ 0.39; passive ideation MZ 0.46, DZ 0.34) were similar to those for 'any suicidal ideation'.

\section{The heritability of suicidal ideation that is independent of depression}

Model 1 (Table 5) shows significant association between ideation in the proband (twin 1) with the co-twin (twin 2), showing that familial factors (i.e. genetic, A, or shared-family environmental factors, C), contribute to suicidal ideation. Model 2 shows that there is still a familial contribution to suicidal ideation after controlling for the familial effect of depression. The effect of zygosity is significant in Model 2, showing there is a genetic contribution to suicidal ideation that is independent of the heritability of depression. However, when analysed separately by gender, this was statistically significant in men only. This suggests that amongst women, the genetic component of suicidal ideation (Table 4) is largely mediated through depression.

Models 3 and 4 of Table 5 show that, in men, the heritable contribution to suicidal ideation is independent from any heritable contribution to alcohol abuse, as well as being independent from any heritable contribution to depression.

\section{Socio-demographic factors associated with suicidal ideation, independent of genetic influences}

Several of the socio-demographic factors studied were still associated with suicidal ideation when examined within pairs of MZ twins, indicating the causal pathway is operating via non-shared environmental factors, $E$, rather than being confounded by genes or the wider family environment (Table 6). These included living without a marital partner, stressful life events and standard of living. For years at school, urban residence and level of employment in the past year, the strength of association with suicidal ideation diminished when 
Table 5. Cross-twin logistic regression to examine the heritability of ideation independent of the heritability of depression

\begin{tabular}{|c|c|c|c|c|c|c|c|}
\hline & \multicolumn{7}{|c|}{ Predicting Twin 1 ideation from Twin 2 ideation } \\
\hline & $\begin{array}{l}\text { 1. Controlling for age, } \\
\text { sex and ethnicity OR } \\
(95 \% \mathrm{CI})\end{array}$ & $\begin{array}{l}\text { 2. As Model 1, plus } \\
\text { controlling for Twin } 2 \\
\text { depression OR }(95 \% \mathrm{CI})\end{array}$ & $\begin{array}{l}\text { 3. As Model 1, plus } \\
\text { controlling for Twin } 2 \\
\text { alcohol abuse OR } \\
(95 \% \text { CI) }\end{array}$ & $\begin{array}{l}\text { 4. As Model 1, plus } \\
\text { controlling for Twin } 2 \\
\text { depression and alcohol } \\
\text { abuse OR }(95 \% \mathrm{CI})\end{array}$ & $\begin{array}{l}\text { Effect of } \\
\text { zygosity in } \\
\text { Model } 2\end{array}$ & $\begin{array}{l}\text { Effect of } \\
\text { zygosity in } \\
\text { Model } 3\end{array}$ & $\begin{array}{l}\text { Effect of } \\
\text { zygosity in } \\
\text { Model } 4\end{array}$ \\
\hline All & $3.80(2.90-4.99)$ & $3.52(2.67-4.64)$ & $3.73(2.88-4.97)$ & $3.51(2.65-4.63)$ & $\begin{array}{c}Z=2.80 \\
p=0.005\end{array}$ & $\begin{aligned} Z & =2.66 \\
p & =0.008\end{aligned}$ & $\begin{aligned} Z & =2.73 \\
p & =0.006\end{aligned}$ \\
\hline $\mathrm{MZ}$ & $5.68(3.72-8.69)$ & $5.24(3.41-8.05)$ & $5.63(3.68-8.61)$ & $5.20(3.39-7.99)$ & & & \\
\hline DZ (incl DZOS) & $2.71(1.88-3.91)$ & $2.51(1.72-3.65)$ & $2.68(1.86-3.87)$ & $2.49(1.71-3.62)$ & & & \\
\hline Men (excl DZOS) & $4.19(2.26-7.79)$ & $3.84(2.02-7.31)$ & $4.06(2.17-7.59)$ & $3.76(1.96-7.19)$ & $\begin{array}{r}Z=2.58 \\
p=0.01\end{array}$ & $\begin{array}{c}Z=2.46 \\
p=0.014\end{array}$ & $\begin{array}{l}Z=2.57 \\
p=0.010\end{array}$ \\
\hline MZM & $8.07(3.59-18.11)$ & $7.17(3.16-16.29)$ & $7.86(3.48-17.74)$ & $7.09(3.10-16.23)$ & & & \\
\hline DZM & $1.34(0.42-4.27)$ & $1.27(0.38-4.22)$ & $1.24(0.37-4.11)$ & $1.19(0.35-4.09)$ & & & \\
\hline Women (excl DZOS) & $4.22(2.89-6.18)$ & $3.94(2.68-5.81)$ & $4.22(2.89-6.18)$ & $3.94(2.68-5.81)$ & $\begin{array}{r}Z=1.09 \\
p=0.28\end{array}$ & $\begin{array}{r}Z=1.04 \\
p=0.299\end{array}$ & $\begin{array}{c}Z=1.09 \\
p=0.277\end{array}$ \\
\hline MZF & $4.96(3.04-8.08)$ & $4.64(2.84-7.57)$ & $4.96(3.05-8.08)$ & $4.64(2.84-7.57)$ & & & \\
\hline DZF & $3.16(1.70-5.88)$ & $2.95(1.55-5.62)$ & $3.16(1.70-5.88)$ & $2.95(1.55-5.62)$ & & & \\
\hline DZ OS & $2.74(1.63-4.60)$ & $2.54(1.50-4.30)$ & & & & & \\
\hline
\end{tabular}

DZOS, DZ opposite sex pairs.

Models 3 and 4 have been included for women for completeness; though as we note earlier, alcohol abuse is very rare in women in this population so these models are largely unchanged after accounting for female alcohol abuse. 
Table 6. Socio-demographic and environmental associations independent of genes (monozygotic twin differences)

\begin{tabular}{|c|c|c|c|c|}
\hline \multirow{2}{*}{$\begin{array}{l}\text { Socio-demographic/ } \\
\text { Environmental factor }\end{array}$} & \multirow{2}{*}{$\begin{array}{l}\text { Number of pairs } \\
\text { discordant for the } \\
\text { environmental } \\
\text { variable }\end{array}$} & \multicolumn{3}{|c|}{$\begin{array}{l}\text { OR ( } 95 \% \mathrm{CI} \text { ) for the association between within-pair difference } \\
\text { in (i) suicidal ideation and (ii) social/ demographic factors }\end{array}$} \\
\hline & & All & Men & Women \\
\hline Widowed/Separated/Divorced & 46 & $3.76(1.94-7.30)$ & $10.19(2.44-42.62)$ & $2.59(1.26-5.36)$ \\
\hline Years at school $(\geqslant>10)$ & 87 & $1.18(0.69-2.02)$ & $1.25(0.50-3.11)$ & $1.17(0.59-2.32)$ \\
\hline Urbanisation & 36 & $0.95(0.40-2.25)$ & $2.08(0.35-12.36)$ & $0.77(0.31-1.94)$ \\
\hline $\begin{array}{l}\text { Underemployed }(2-10 \mathrm{mths} \\
\text { work in past } 12 \mathrm{mths})\end{array}$ & 118 & $1.35(0.85-2.14)$ & $0.87(0.37-2.03)$ & $1.63(0.94-2.84)$ \\
\hline Unemployed (0-1mths) & 174 & $0.97(0.66-1.43)$ & $0.47(0.18-1.25)$ & $1.10(0.74-1.62)$ \\
\hline Life event $^{a}$ & 390 & $1.50(1.22-1.84)$ & $1.43(0.99-2.06)$ & $1.54(1.20-1.97)$ \\
\hline $\begin{array}{l}\text { Standard of living (binary, } \\
\text { lower } 2 / 5^{\text {th }} v \text {. upper } 3 / 5 \text { th) }\end{array}$ & 169 & $1.63(1.10-2.40)$ & $2.36(1.18-4.75)$ & $1.40(0.88-2.23)$ \\
\hline
\end{tabular}

Based on $N=824$ pairs of MZ twins; of whom 151 pairs (18.3\%) were discordant for suicidal ideation.

Note no significant sex interaction terms were found. Bold values indicate $p<0.05$.

${ }^{a}$ Life events were categorized into 0,1 , or 2 or more events per person.

looking at differences within MZ pairs; i.e. these associations were no longer statistically significant when familial effects (A and C) had been controlled for.

\section{Discussion}

We aimed to examine the prevalence and risk factors for suicidal ideation in a population-representative sample from an LMIC and to investigate the relative contribution of genetic and environmental influences on suicidal ideation. Key findings were that $13 \%$ of male twins and singletons and almost $22 \%$ of females reported suicidal ideation in their lifetime, and this was mainly passive ideation (12\%) rather than active ideation, which had been experienced by $6 \%$ [similar to the $7.3 \%$ prevalence reported for Colombo in the SUPRE-MISS study (Bertolote et al. 2005), but lower than the $9.2 \%$ average reported in the World Mental Health survey, where country prevalence ranged from 3.0 to $15.9 \%$ (Nock et al. 2008)].

There was no difference in the prevalence of suicidal ideation for singletons or twins or across zygosity groups. This is important, because previous literature suggests a modest protective effect of being a twin on completed suicides (Tomassini et al. 2003), which would undermine the generalizability of twin findings regarding suicidal ideation to the wider population.

\section{Suicidal ideation as a familial trait}

We showed higher concordance of suicidal ideation among MZ than DZ twins, consistent with a genetic influence on suicidal ideation. This translated to a significant contribution of additive genetic factors (heritability estimate: $57 \%$ ) for suicidal ideation. Non-shared environmental effects also contributed substantially to the risk of suicidal ideation $(43 \%)$ whereas the effect of shared family environment did not.

Twin studies of completed suicide and attempted suicide in Europe and the USA (Roy et al. 1991; Roy et al. 1995; Roy \& Segal, 2001) have shown similar effects. Studies of suicidal ideation are rare. An Australian twin study (Statham et al. 1998) estimated a similar genetic contribution (45\%) to the variance in suicidal thoughts and behaviours, with a higher estimate of heritability (55\%) obtained when serious suicide attempts were considered. After controlling for socio-demographic, personality, psychiatric, traumatic event and family history variables, a history of suicide attempt or persistent suicidal thoughts in a co-twin remained a significant predictor of suicidal thoughts and behaviour in $\mathrm{MZ}$ twins, but not in $\mathrm{DZ}$ twin pairs, implying some genetic contribution to suicidal thoughts or behaviours independent of clinical and social covariates.

In twin men from the US Vietnam Era Twin Registry, suicidal ideation was found to be influenced by additive genetic ( $47 \%$ ) and non-shared environmental (53\%) effects (Fu et al. 2002). This study also showed some of the heritability of suicidal ideation was independent of psychiatric disorders with $36 \%$ additive genetic and $64 \%$ non-shared environmental contributions remaining after adjustment (Fu et al. 2002).

Analysing published data from Roy et al. (1991), McGuffin et al. (2001) estimated heritability for completed suicide to be $43 \%(25-60 \%)$. This paper also 
suggested that the overlap between genes predisposing to affective disorders and those related to suicidality is unlikely to be complete, as only about half those completing suicide had a diagnosis of depression.

We found that in women the genetic component appeared to be largely mediated through depression; but in men there was a significant genetic effect independent of depression and alcohol abuse. In men, other unmeasured forms of psychopathology (e.g. externalizing traits), which are genetically driven, may make a contribution to suicidal ideation. Our study demonstrates a heritable component of suicidal ideation, which is incompletely explained by measured psychopathology, suggesting a potential direct heritable effect on suicidal behaviour. This emphasizes the clinical importance of family history of suicidal behaviours, even in patients without any diagnosed psychiatric disorder. However, there is a need for further studies to assess the aetiological overlap between suicidal behaviours and a range of other psychiatric disorders, for example a recent register study has shown that patients with Chronic Fatigue Syndrome have a higher mortality from suicide than the general population (Roberts et al. 2016).

\section{Environmental associations with suicidal ideation}

Examining the differences within MZ pairs of twins allowed us for the first time to identify environmental associations of suicidal ideation that are independent of genetic factors. Loss of marital relationships in both sexes, stressful life events in women and lower standard of living in men were associated with suicidal ideation independent of genetic effects. This means these are true environmental effects rather than markers of inheritance or shared upbringing. These factors are typically found to be correlated with depression, but previous analyses in this sample found the only associations of depression that were independent of genetic effects were in men not women: low standard of living, leaving school at a young age and stressful life events (Ball et al. 2010a). This suggests different aetiological pathways leading to suicidal ideation compared with depression.

For education (years at school), urbanization and level of employment in the last year, there was no such environmentally-mediated association with suicidal ideation. This suggests that the latter three environmental variables are confounded - perhaps a genetic factor makes people more likely to experience this environmental variable and to experience suicidal ideation, or perhaps it is a marker of some other aspect of family upbringing that is associated with both the environmental variable and suicidal ideation. For example, genetic factors relating to low IQ might mean an individual leaves school early and moves to a town to look for employment but remains underemployed and independently many studies suggest that low IQ is associated with an elevated risk of suicide (Gunnell et al. 2005).

Furthermore, the important cultural factors that account for differences in alcohol (Zavos et al. 2015) and tobacco consumption (Zavos et al. 2012) amongst males and females means that the association we observed for these variables with suicidal ideation was driven by effects in men, and cannot be generalized to both sexes.

\section{Limitations}

We used a population-based twin sample with exceptionally high participation rates, making our results more generalizable than many previous twin studies based on volunteer registries. However the epidemiological analyses are based on cross-sectional data and therefore causation cannot be inferred. Life-event data were measured over the past-year (whereas suicidal ideation and depression were measured on a lifetime-ever basis), further limiting our ability to ascertain causal links from the epidemiological data.

Despite presenting the largest study of its kind from a LMIC, our power to detect sex differences in ACE models was low and we present models, which equate model parameters between men and women. Our genetic analyses were also limited to 'any suicidal ideation' rather than examining active and passive ideation separately. Finally, power was too low to run bivariate ACE models, so instead we used logistic regression models to explore the aetiology of the associations between suicidal ideations on the one hand, and depression, alcohol abuse and socio-demographic or environmental factors on the other.

As suicidal ideation, intentions, plans, behaviours and attempts are on a spectrum it is difficult to find valid and appropriate, as well as culturally-sensitive, screening questions for suicidal ideation that are comparable with other international studies (Samaraweera et al. 2010). However this study was preceded by local research to investigate whether inhabitants of a suburb of Colombo would volunteer their life weariness and suicidal ideation (Sumathipala et al. 2004) and concluded that individuals would disclose them if asked directly.

\section{Conclusions}

The moderate degree of heritability of suicidal ideation in this twin study in Sri Lanka was similar to estimates made for any suicidal behaviour (ideation or attempts) or completed suicides from other population-based 
epidemiological twin studies conducted in different parts of the world. Twin/non-twin status was associated with neither passive nor active suicidal ideation, supporting generalizability of the findings to the general population. In addition to deepening the understanding of heritable components to suicidal ideation, what is apparent is that social adversity (life events, marital breakup and socio-economic disadvantage) are important environmental risk factors. which act independently from genetic risk.

\section{Acknowledgements}

The Wellcome Trust (Grant Number 069629) provided funding for the study, and had no further role in study design; in the collection, analysis and interpretation of data; in the writing of the report; and in the decision to submit the paper for publication. The Institute for Research and Development, Sri Lanka, provided infrastructural support. R.D. is funded by a Clinician Scientist Fellowship from the Health Foundation in partnership with the Academy of Medical Sciences. M.H. receives salary support from the National Institute for Health Research (NIHR) Mental Health Biomedical Research Centre at South London and Maudsley NHS Foundation Trust and King's College London and is Director of the Centre. The views expressed are those of the author(s) and not necessarily those of the NHS, the NIHR or the Department of Health.

\section{References}

APA (2000). American Psychiatric Association. Diagnostic and Statistical Manual of Mental Disorders, 4th edn. - Text Revision (DSMIV-TR). Washington, DC.

Ball H, Siribaddana S, Sumathipala A, Kovas Y, Glozier N, McGuffin P, Hotopf M (2010a). Environmental exposures and their genetic or environmental contribution to depression and fatigue: a twin study in Sri Lanka. BMC Psychiatry 10, 13.

Ball HA, Siribaddana SH, Kovas Y, Glozier N, McGuffin P, Sumathipala A, Hotopf M (2010b). Epidemiology and symptomatology of depression in Sri Lanka: a cross-sectional population-based survey in Colombo District. Journal of Affective Disorders 123, 188-196.

Bertolote JM, Fleischmann A (2002). Suicide and psychiatric diagnosis: a worldwide perspective. World Psychiatry 1, 181-185.

Bertolote JM, Fleischmann A, De Leo D, Bolhari J, Botega N, De Silva D, Tran Thi Thanh H, Phillips M, Schlebusch L, Varnik A, Vijayakumar L, Wasserman D (2005). Suicide attempts, plans, and ideation in culturally diverse sites: the WHO SUPRE-MISS community survey. Psychological Medicine 35, 1457-1465.

Bifulco A, Bernazzani O, Moran PM, Jacobs C (2005). The childhood experience of care and abuse questionnaire
(CECA.Q): validation in a community series. British Journal of Clinical Psychology 44, 563-581.

Brent D (2010). What family studies teach us about suicidal behavior: implications for research, treatment, and prevention. European Psychiatry 25, 260-263.

Brent DA, Bridge J, Johnson BA, Connolly J (1996). Suicidal behavior runs in families. A controlled family study of adolescent suicide victims. Archives of General Psychiatry 53, 1145-1152.

Brent DA, Melhem N (2008). Familial transmission of suicidal behavior. Psychiatric Clinics of North America 31, 157-177.

Brugha TS, Cragg D (1990). The list of threatening experiences: the reliability and validity of a brief life events questionnaire. Acta Psychiatrica Scandinavica 82, 77-81.

Chalder T, Berelowitz G, Pawlikowska T, Watts L, Wessely S, Wright D, Wallace EP (1993). Development of a fatigue scale. Journal of Psychosomatic Research 37, 147-153.

Fu Q, Heath AC, Bucholz KK, Nelson EC, Glowinski AL, Goldberg J, Lyons MJ, Tsuang MT, Jacob T, True MR, Eisen SA (2002). A twin study of genetic and environmental influences on suicidality in men. Psychological Medicine 32, 11-24.

Gunnell D, Magnusson PK, Rasmussen F (2005). Low intelligence test scores in 18 year old men and risk of suicide: cohort study. British Medical Journal 330, 167.

Hawton K (2014). Suicide prevention: a complex global challenge. Lancet Psychiatry 1, 2-3.

Lieb R, Bronisch T, Hofler M, Schreier A, Wittchen HU (2005). Maternal suicidality and risk of suicidality in offspring: findings from a community study. American Journal of Psychiatry 162, 1665-1671.

Maciejewski DF, Renteria ME, Abdellaoui A, Medland SE, Few LR, Gordon SD, Madden PA, Montgomery G, Trull TJ, Heath AC, Statham DJ, Martin NG, Zietsch BP, Verweij KJ (2017). The association of genetic predisposition to depressive symptoms with non-suicidal and suicidal self-injuries. Behavioural Genetics 47, 3-10.

McGuffin P, Marusic A, Farmer A (2001). What can psychiatric genetics offer suicidology? Crisis 22, 61-65.

Mirkovic B, Laurent C, Podlipski MA, Frebourg T, Cohen D, Gerardin P (2016). Genetic association studies of suicidal behavior: a review of the past 10 years, progress, limitations, and future directions. Frontiers in Psychiatry 7, 158.

Nock MK, Borges G, Bromet EJ, Alonso J, Angermeyer M, Beautrais A, Bruffaerts R, Chiu WT, de Girolamo G, Gluzman S, de Graaf R, Gureje O, Haro JM, Huang Y, Karam E, Kessler RC, Lepine JP, Levinson D, Medina-Mora ME, Ono Y, Posada-Villa J, Williams D (2008). Cross-national prevalence and risk factors for suicidal ideation, plans and attempts. British Journal of Psychiatry 192, 98-105.

O'Connor RC, Nock MK (2014). The psychology of suicidal behaviour. Lancet Psychiatry 1, 73-85.

Reynolds CA, Fiske A, Fratiglioni L, Pedersen NL, Gatz M (2006). Heritability of an age-dependent categorical phenotype: cognitive dysfunction. Twin Research and Human Genetics 9, 17-23.

Roberts E, Wessely S, Chalder T, Chang CK, Hotopf M (2016). Mortality of people with chronic fatigue syndrome: 
a retrospective cohort study in England and Wales from the South London and Maudsley NHS Foundation Trust Biomedical Research Centre (SLaM BRC) Clinical Record Interactive Search (CRIS) Register. Lancet 387, 1638-1643.

Robins LN, Wing J, Wittchen HU, Helzer JE, Babor TF, Burke J, Farmer A, Jablenski A, Pickens R, Regier DA, et al. (1988). The Composite International Diagnostic Interview. An epidemiologic instrument suitable for use in conjunction with different diagnostic systems and in different cultures. Archives of General Psychiatry 45, 1069-1077.

Roy A, Segal NL (2001). Suicidal behavior in twins: a replication. Journal of Affective Disorders 66, 71-74.

Roy A, Segal NL, Centerwall BS, Robinette CD (1991). Suicide in twins. Archives of General Psychiatry 48, 29-32.

Roy A, Segal NL, Sarchiapone M (1995). Attempted suicide among living co-twins of twin suicide victims. American Journal of Psychiatry 152, 1075-1076.

Samaraweera S, Sumathipala A, Siribaddana S, Sivayogan S, Bhugra D (2010). Prevalence of suicidal ideation in Sri Lanka. Crisis 31, 30-35.

Schosser A, Butler AW, Ising M, Perroud N, Uher R, Ng MY, Cohen-Woods S, Craddock N, Owen MJ, Korszun A, Jones L, Jones I, Gill M, Rice JP, Maier W, Mors O, Rietschel M, Lucae S, Binder EB, Preisig M, Perry J, Tozzi F, Muglia P, Aitchison KJ, Breen G, Craig IW, Farmer AE, Muller-Myhsok B, McGuffin P, Lewis CM (2011).

Genomewide association scan of suicidal thoughts and behaviour in major depression. PLoS ONE 6, e20690.
Siribaddana SH, Ball HA, Hewage SN, Glozier N, Kovas Y, Dayaratne D, Sumathipala A, McGuffin P, Hotopf M (2008). Colombo Twin and Singleton Study (CoTASS): a description of a population based twin study of mental disorders in Sri Lanka. BMC Psychiatry 8, 49.

Statham DJ, Heath AC, Madden PAF, Buckholz KK, Bierut L, Dinwiddie SH, Slutske WS, Dunne MP, Martin NG (1998). Suicidal behaviour: an epidemiological and genetic study. Psychological Medicine 28, 839-855.

Sumathipala A, Siribaddana S, Samaraweera SD (2004). Do patients volunteer their life weariness and suicidal ideations? A Sri Lankan study. Crisis 25, 103-107.

Tomassini C, Juel K, Holm NV, Skytthe A, Christensen K (2003). Risk of suicide in twins: 51 year follow up study. British Medical Journal 327, 373-374.

WHO (2014). Preventing suicide: A global imperative. World Health Organization: Geneva.

Williams RL (2000). A note on robust variance estimation for cluster-correlated data. Biometrics 56, 645-646.

Zavos HM, Kovas Y, Ball HA, Ball D, Siribaddana SH, Glozier N, Sumathipala A, McGuffin P, Hotopf M, Rijsdijk FV (2012). Genetic and environmental etiology of nicotine use in Sri Lankan male twins. Behavioural Genetics 42, 798-807.

Zavos HM, Siribaddana S, Ball HA, Lynskey MT, Sumathipala A, Rijsdijk FV, Hotopf M (2015). The prevalence and correlates of alcohol use and alcohol use disorders: a population based study in Colombo, Sri Lanka. BMC Psychiatry 15, 158. 